\title{
Power Relations Revealed by the Kinship Terms Based on the Tones of Other Relatives
}

\author{
Lijing Wang \\ No.5 Jinyuanzhuang Road, Shijingshan District, Beijing, P.R. China \\ 2268248032@qq.com
}

Keywords: The kinship terms based on the tones of other relatives; Power relations; Culture

\begin{abstract}
The kinship terms based on the tones of other relatives are the unique cultural characteristics of China. From ancient times, China has attached great importance to ethnic relations, so the appellation of relatives is very diverse. As a special part of kinship terms, kinship terms based on the tones of other relatives indicate such a language phenomenon that the speaker addresses his or her own relatives is not based on the kinship, but on the relationship between others and the one the kinship term indicates. But sometimes the appellation of relatives will be affected by power and then change. At this time the address is no longer a direct response to kinship, but the reaction of the relations of seniority, status, wealth or other factors. This paper intends to explore the power relations among speakers from the kinship terms based on the tones of other relatives and the reasons for this phenomenon.
\end{abstract}

\section{Introduction}

The so-called kinship terms based on the tones of other relatives actually refer to the speaker addressing other relatives by using the tone of certain relative.[1]China is a great country in agriculture, and its characteristic is to focus on clan relations so that the diversity of kinship appellation is great. Sometimes, even we address the same person, different people may have different ways of addressing. For example, in China, when a man calls his wife, he may say "孩儿 他妈"(kid's mom), while others perhaps call his wife,"他姥姥"(his grandmother).However, sometimes the appellation of relatives will reveal certain power relations by different seniority in the family or clan, different status, different wealth or other factors."Power" as the term of social linguistics, first introduced by psychologist Roger Brown, mainly refers to clear distance between the speakers on the social status, identity and power.[2]At times, it will be reflected through seniority in the family or clan, social status, wealth and other aspects. Throughout the whole research about appellation, it can be seen that there are many studies about that, while, as for the kinship terms based on the tones of other relatives, the articles are few. What is more, even up to now, seldom combines the power relations with the kinship terms based on the tones of other relatives. Hence, this paper tries to explore the relationship between the power relations between speakers and the relative reasons for forming this appellation.

\section{Research Value and Literature Review}

Research Value. Just as Lyons, a British linguist, said that "The language of a given society is part of the culture of this society, and the differences in words of each language can reflect the important cultural features of the social objects, customs and activities of the language".[3]As we all know, kinship appellation is a major feature of Chinese culture. And in the kinship appellation, the kinship terms based on the tones of other relatives are indispensable. If people want to know the Chinese culture better, then to understand the kinship terms based on the tones of other relatives of China is the key point.

In addition, with the process of globalization of the world and the exchange between countries increasingly closing, the value of translation also becomes more and more important. Wanting to translate well, people have to understand the unique culture of the target language, which is 
essential. The kinship terms based on the tones of other relatives are unique phenomena in China, therefore, the study from this perspective is of great value.

Literature Review. Guide of Chinese Family Appellation (formerly known as the Chinese Kinship System) was written by Feng Hanjin in the 1930s, and in the chapter three, section six, he focused on the impact of the term "从儿称" (addressing based on the tones of kids) on the development of Chinese kinship appellation and thought that as idiomatic usage and based on the kinship and appellation of relatives, the kinship terms based on the tones of other relatives is euphemistic term for those relatives who are difficult to being addressed, such as the husband to address his wife, a father to address his own father and so on. Also, the kinship terms based on the tones of kids can give a clear explanation to the social meaning of the appellation of relatives, such as舅(mother's brother), 伯(father's elder brother), 叔(father's younger brother), 姑(father's sister), 姨(mother's sister), 婶(the wife of father's younger sister), 公(husband's father), 婆(husband's

Besides, Feng Hanji firstly explored the kinship terms based on the tones of kids as a system in his article The Kinship Terms Based on the Tones of Other Relatives as a Special Component of the System of Relatives.[5] Zhao Yuanren also mentioned the kinship terms based on the tones of kids in his book The Appellation in Chinese Language, and thought that"公公"(husband's father) and"婆 婆"(husband's mother) originally are also a kind of the kinship terms based on the tones of kids.[6] Wu Tie-ping, in his essay The Kinship Terms Based on the Tones of Kids and Related Phenomena in Chinese Language, pointed out that in many languages people will use the address that young people to elders as the name of elders or peers of wives or husbands. [7]

Although there are many studies on kinship terms, there are few who study the kinship terms based on the tones of other relatives, not alone the combination the kinship terms based on the tones of other relatives with power relatives. Most perspectives that many scholars choose are from culture, appellation on dialects or translation.

\section{Power Relations Revealed by the Kinship Terms Based on the Tones of Other Relatives}

Power Relations Revealed by the Kinship Term Based on the Tones of Husbands. In China's traditional marriage system, women after marriage must live in the husband's family (except for the groom marries into and lives with the bride's family), and "在家从父, 出嫁从夫, 夫死从子"(Be obedient to your father at home, obey your husband after you get married, and submit your son when husband died), so when the wife addresses her husband's family, she will naturally use the kinship terms based on the tones of other relatives. For example, she need call her husband's mother as mother, her husband's father as father, her husband's brother as brother and so on. The specific examples are as follows:

(1) Seeing her mother-in-law becoming more and more angry, Jin Gui doesn't want to blow it into a major controversy, so she thought of a way, and still smiled and said, "Mother! Please do not get angry! If you do not want to move down, I will help you move up again![8]

This is called the kinship terms based on the tones of husbands. Just think of it, if she is not the daughter-in-law of this family, how can Jin Kui now call her mother-in-law "mother"? Such address can show the relations of seniority in the power relations. The mother-in-law is elder, and the daughter-in-law is younger generation, so it is necessary for the younger to show respect to the elder.

(2) At dawn, Ju Wa said to her mother-in-law," Mother, I will go to live in the store today."[9]

$\mathrm{Ju} \mathrm{Wa}$, the ex-wife of Lu Ming, is a rural woman, and her thought is too old because even if she divorces, she still uses the kinship terms based on the tones of husbands to call her mother-in-law mother. This kinship terms based on the tones of husbands reflects the respect of the younger to the elders.

(3) At this time, He Fengying stopped working, turned out from the back of the hearth, and said, "brother, I have a distant niece in my mother's family, and her mother died early, so she has brought up by her father.[10] 
In this sentence, "brother" refers to the speaker's brother of husband. Here, according to the kinship terms based on the tones of husbands, the speaker addresses the man brother, from which we can see the status of women in the ancient time of China. Everything the wives have to listen to their husbands and follow their husbands.

Power Relations Revealed by the Kinship Term Based on the Tones of Kids. The kinship term based on the tones of kids means to address somebody but standing on the kids' position, that is they need to follow the appellation of kids. E.g

(1) Gou Er said, "The grandma is right, moreover, you have seen the lady once."[11]

"Grandma" should be called by Gou Er's son, but here Gou Er call his mother-in-law grandma is the kinship terms based on the tones of kids. At that situation, Gou Er needs the grandmother to go to the Jia mansion and ask for money, therefore he automatically descends his rank, which is also a kind of power relation, because at that moment grandma's status is higher than Gou Er's.

(2) Wu Yushan looked up suddenly."His aunt ... after all is the city dweller and has great experiences. Also, she is very calm down when facing problems. Although very sad, she is not like our country folk, because we will cry without thinking when facing this situation. The aunt is pretty calm."His wife said with admiration.[12]

Here "aunt" is the appellation following their son. This aunt is the city person, while she is countryman, and Wu's wife feels that the aunt's status is higher than their, so she uses the kinship terms based on the tones of kids, which can manifest the power relations on the social status.

(3) Yang Jinshan shouted, "elder nephew, do not break your aunt! Do you hear me? Bastard, you deaf!"[13]

In this case, the speaker Yang Jinshan is the hearer Yang Tianqing's uncle, so it is no use talking polite for Yang Jinshan to Yang Tianqing, and Yang Jinshan shouted and reminded his nephew that the woman on his back is Yang Tianqing's aunt, his wife and Yang Jinshan's elder, so he need be careful. This reflects the priority in the status that is higher than the younger generation, which means the elder can choose what they want to address the younger.

(4) Lady Dowager said to Shi Xiangyun, "After celebrating your sister Bao's birthday and watching the play, then you can go back."[11] "Your Bao sister" is the kinship terms based on the tones of kids, that is, the speaker addresses the third party from the hearer's perspective. This sort of situation is always used by the people who talk to the kids or the people who are in the low status. According to Zhao Yanren, it is humble to talk from his own view, but deliberately condescending to talk from the hearer's view.[14] Because Xue Baochai's status is higher that that of Shi Xiangyun, Lady Dowager used this appellation.

Power Relations Revealed by the Kinship Term Based on the Tones of Uncle. The kinship term based on the tones of uncle refers to the speakers address themselves from the perspective of their uncle, thus it can emphasize the relationship between the speakers with the listener and narrow the distance between then. E.g.

(1)"Uncle, you are not the one you used to be. Could you talk about the business skills to your nephew andbroaden my horizons?"

"Your nephew" here is the kinship term based on the tones of uncle. The speaker's uncle now earns too much money, so his identity and status are different from the one he used to be. Hence, the speaker wants to use this appellation to get closer to his uncle, which is a power relation based on wealth and identity.

Power Relations Revealed by the Kinship Term Based on the Tones of Niece. The kinship term based on the tones of niece means that the speakers address themselves or others from the niece's point of view. E.g.

Lady Wang said,"Your uncle today fasts. You can meet him another day. But there is a word I have to tell you that your three sisters are very nice, and you can later read, needle or occasionally joke with them, but the most worrying thing is that I have a naughty son, who is the 'devil' at home. Today, he goes to the temple and has not come back. You will see him in the evening...".[11]

In the example above,"you" refers to Lin Daiyu, and Lin's uncle, Jia Zheng, is Lady Wang's husband. Here utilizes the kinship term based on the tones of niece. Lin is the granddaughter in Jia 
mansion with certain status, therefore, when Lady Wang talks Jia Zhang with Lin, she can say "you uncle", because Lin nearly has the same identity and status with Lady Wang. However, if Lady Wang talks Jia Zhang with other maidservants, she will say "master."

\section{The Origin of the Kinship Terms Based on the Tones of Other Relatives}

Marriage System. China's marriage system has great influence on the kinship terms based on the tones of other relatives. For example, before marriage, women can call parents of their husbands casually, but after that, they need to follow their husbands and address their mother-in-law or father-in-law mother or father. Besides, in ancient times, men are dominate, and women have to obey the three obediences and the four virtues--- three obedience (in ancient China a woman was required to obey her father before marriage, and her husband during married life and her sons in widowhood) and four virtues (fidelity, physical charm, propriety in speech and efficiency in needle work).Hence, there are the kinship terms based on the tones of husbands and kids.

Moral Concept. China is a state of etiquette since ancient times, so people pay great attention to ethics. A long time ago, the provision of ethics is that the men and women are different, men have higher status than women, and women have always been considered as men's accessories. So the addresses then like "kid's mom" or kid's name plus the word "mom" are very common. Undoubtedly, there will appear the kinship term based on the tones of kids. Apart from this, in the woman's side, the younger generation should address mother's brother "舅舅"(uncle) no matter their uncle is older or younger than their mother. While, in the man's side, kids have to address their father's elder brother"伯伯"（uncle in English）and younger brother"叔叔"（uncle in English).

Family System. Regardless of in the past or at present, the head of the family is mostly males. In fact, to some extent, there are some ideas that are still not improved. In many cases, men are favorite, so up to now, the kinship term based on the tones of husband still exists.

\section{Conclusion}

This paper studies the kinship terms based on the tones of husband, of kids, of uncle or of niece, and finds that to a certain extent, they can reflect the differences of identity, wealth, status, rank, seniority or other power relations between speakers. The reasons of these phenomena are because of the marriage system, moral values and family system in ancient China.

\section{References}

[1] H.Chen and G.H. Chen: Contemporary Linguistics, (2001) No.3, p.175. (In Chinese)

[2] R. Li and X.Q. Liu: Journal of Guangxi University for Nationalities, (2006) No.5, p.154-156. (In Chinese)

[3] H. Wen: Journal of Hexi University, Vol. 23(2007) No.1, p.107. (In Chinese)

[4] H.J. Feng: A Guide to Chinese Relatives Appellation.(Shanghai Literature and Art Publishing Group, China 1989:), p.62. (In Chinese)

[5] H.J. Feng: American Anthropologist, (1936), p.38, 59-66.

[6] Y.R. Zhao: Symposium of Zhao Yuanren (Stanford University Press, the United States 1976), p.339. (In Chinese)

[7] T.P. Wu: Journal of Chinese Linguistics, Vol.2 (1984), p.242-258. (In Chinese)

[8] S.L. Zhao: Family Heirloom (World publishing company, China 1952). (In Chinese)

[9] P.A. Jia: Gao Lao Zhuang (Changjiang Literature and Art Publishing Group, China 2015). (In Chinese) 
[10]L. Yao: The Common World (Beijing October Literature Publishing House, China 2013). (In Chinese)

[11]X.Q. Cao: The Story of the Stone. (People's Literature Publishing House, China 2010). (In Chinese)

[12]Z.S. Chen: Weightless (Changjiang Literature and Art Publishing Group, China2012). (In Chinese)

[13]H. Liu: Ju Dou. (Social Sciences in China Press, China 1993). (In Chinese)

[14] Y.R. Chao: Aspects of Chinese Social Linguistics. (Standford University Press, China 1976), p.335. 